Revista Destaques Acadêmicos, Lajeado, v. 11, n. 1, 2019. ISSN 2176-3070

DOI: http://dx.doi.org/10.22410/issn.2176-3070.v11i1a2019.2141

http://www.univates.br/revistas

\title{
A EVOLUÇÃO DO ATENDIMENTO: UMA ANÁLISE NA EXPERIÊNCIA DE CONSUMO DOS CLIENTES DO VAREJO FÍSICO DA CONSTRUÇÃO CIVIL
}

\author{
Henrique Adolfo Klamt ${ }^{1}$
}

\begin{abstract}
Resumo: O artigo apresenta um estudo sobre as experiências de consumo no varejo da construção civil. Para isso, foi realizado uma pesquisa quantitativa na cidade de Teutônia e imediações, com uma amostra de 185 respondentes. Os resultados mostraram que o público, na sua maciça maioria, prefere comprar seus materiais de construção por meio de vendas assessoradas. Contudo, a análise mostrou também que os mesmos entrevistados valorizam os benefícios obtidos de uma compra por autosserviço. Como sugestão para as implicações gerenciais, é sugerido um modelo híbrido entre autoatendimento e venda consultiva, otimizando assim os benefícios de cada um.
\end{abstract}

Palavras-chave: Marketing. Marketing de Experiências. Experiências de consumo. Autosserviço. Venda Consultiva.

\section{INTRODUÇÃO}

Com a evolução da tecnologia da informação nos últimos anos, novos tipos de negócios surgiram e, consequentemente, outras maneiras de comprar emergiram. As novas plataformas digitais possibilitaram ao público acesso ilimitado a qualquer tipo de informação. Com isso, pode-se dizer que o consumidor brasileiro está cada vez mais consciente e informado sobre os produtos disponíveis no mercado. Visivelmente mais conectada, a população em geral está aderindo a novos padrões de consumo. Usuários da internet aumentam a cada ano segundo dados do Instituto Brasileiro de Geografia e Estatística (IBGE, 2013). Só no Brasil, o acréscimo foi de 2,5 milhões de usuários entre 2012 e 2013.

Perante esses fatos, o varejo físico brasileiro passou por grandes mudanças, principalmente no que se refere ao formato de atendimento aos clientes. Com consumidores cada vez mais conscientes de suas necessidades e

1 Bacharel em Administração e acadêmico do Curso de MBA em Marketing da UNIVATES. haklamt@yahoo.com.br 
aplicabilidades dos produtos, já é possível verificar neles uma independência de atendimento humano. Neste mesmo caminho, a construção civil, especialmente grandes organizações varejistas, também começou a aderir aos novos modelos de venda.

Entretanto, o novo formato de negócio pode ser um problema para o setor em questão. Afinal, o produto é extremamente técnico e de grande valor agregado. Assim, é natural que, eventualmente, os clientes necessitem de consultoria no processo de compra, gerando uma venda consultiva. Nesta linha, o vendedor descobre a necessidade e aconselha (mediante seu conhecimento) a melhor solução dentro de seu portfólio e muitas vezes transmite até expectativas adicionais a sua experiência (LAS CASAS, 2002).

Os dois ambientes de vendas, o consultivo e o autoatendimento, competem por espaço nas empresas e geram diferentes resultados e percepções aos clientes. Com isso, a pesquisa tem como tema a experiência de consumo, ou seja, como os clientes percebem e avaliam as interações com a empresa nos dois tipos de atendimentos mencionados anteriormente. A escolha por essa problemática levou em conta as mudanças que o setor varejista da construção civil sofreu nos últimos anos. Como já dito, a implantação do autoatendimento já começa a ser vista em muitas lojas. E assim, com a ideia de um cliente consciente, o vendedor que antes auxiliava o comprador a entender exatamente sua necessidade, acaba perdendo espaço para prateleiras self-service. Porém, a que ponto tal conduta se torna vantajosa a longo prazo se analisarmos a perspectiva do público da empresa? Afinal, esse novo modelo de negócio vai de encontro aos objetivos de uma organização focada no relacionamento, na qual o sucesso não é medido pela lucratividade e sim pelo grau de proximidade e relacionamento com o seu público. No novo modelo de vendas, as interações humanas seriam eliminadas, porém grande parte da literatura enfatiza que o contato humano é fundamental para relações comerciais (KOTLER, 2007. COBRA, 2010. McKENNA, 1997). Ainda mais, se tratando de produtos de alta complexidade técnica, como no caso dos produtos do segmento da construção civil.

Sendo assim, uma análise de como os clientes avaliam as práticas de venda assessorada e self-service da construção civil é necessária. O estudo pode proporcionar um entendimento mais claro sobre o assunto, ainda mais em ambientes tão concorridos como esse em questão. A pesquisa também permitirá observar erros e acertos dos dois meios de venda que são tema do estudo, para assim se ter uma base do que o público desse segmento espera de lojistas. Nesse contexto, surge a problemática da pesquisa: na percepção dos consumidores da construção civil, qual dos métodos de atendimento, o autosserviço ou a venda consultiva, é o mais indicado? Tendo como objetivo principal descobrir os benefícios e malefícios na percepção dos consumidores da construção civil para cada modelo de negócio. Além disso, o estudo também se propôs a identificar 
quais práticas de atendimento trazem os melhores resultados no quesito relacionamento empresa e cliente.

\section{REFERENCIAL TEÓRICO}

\subsection{Marketing e suas transformações}

Marketing é administrar relacionamentos lucrativos com o cliente de alguma organização. Segundo os autores, existem duas grandes missões norteadoras para o marketing, uma delas é buscar novos clientes, oferecendo a eles o valor proposto do produto ou empresa. O segundo, não menos importante é manter os clientes já existentes, dando a eles o melhor que a empresa tem a oferecer, deixando-os satisfeitos. Contudo, deixar o consumidor satisfeito é insuficiente, é preciso mais que isso, criar conexões emocionais e relacionamentos reais. Portanto, pode-se dizer que fazer marketing, envolve a identificação das necessidades humanas e sociais, em seguida criar estratégias para que essas necessidades sejam supridas (McKENNA, 1997. KOTLER; ARMSTRONG, 2007. HILL, 2010).

Para Madruga (2010) e Gummesson (2010), existem duas frentes conflitantes no marketing, o marketing transacional e o marketing de relacionamento. O primeiro é focado em fechar a venda, ou seja, facilitar uma transação comercial, sem esperar necessariamente que o contato com o cliente se repita. Já o segundo é totalmente o oposto, a venda não é o pilar principal do contato com o cliente, mas sim as interações, esperando que os contatos com o público se repitam constantemente. No segundo, a interação deve ser constante entre as partes, por isso exercer uma boa comunicação (mercadológica, institucional e suporte) é indispensável.

\subsection{Marketing de relacionamento}

O marketing de relacionamento caracteriza-se por ações constantes de interação com o público da empresa, essa conduta se divide em duas etapas, a primeira identifica o que o cliente espera da empresa, o que vai muito além dos produtos que ela comercializa, e então, a empresa entrega o que o mercado espera dela. A segunda parte, é onde a empresa cria valor a seu cliente, sendo essa a parte mais difícil, pois é no valor criado que o público avalia se é vantajoso manter uma relação com a empresa (McKENNA, 1997. GORDON, 1998. MADRUGA, 2010).

Para McKenna (1997), assim como Kotler e Armstrong (2007), um relacionamento com um cliente começa na informação, isto é, conhecer o cliente que a organização irá interagir é fundamental. E para tanto, é preciso saber de suas particularidades, saber de seus desejos, descobrir padrões de consumo, entre outras informações. Em muitos nichos de mercado, os clientes esperam uma relação customizada, querem ser tratados de forma única, e para isso a 
organização precisa manter um banco de dados atualizado de cada consumidor, muitas vezes com a ajuda de um software, conhecido como Customer Relationship Management (CRM). McKenna (1997) acrescenta que o relacionamento com o cliente é o bem mais precioso que a empresa pode ter, e para isso, é preciso saber ouvir o mercado.

\subsection{Marketing de serviços e Marketing Experiencial}

Para apresentarmos um conceito de marketing de serviços, é preciso primeiro conceituar serviços, dito isso, segundo Bitner et al (2011), serviços em termos gerais são atos, processos e atuações oferecidos ou coproduzidos por uma entidade ou pessoa. E serviços não se referem somente a empresas da área, existem setores onde o produto final é um produto tangível, entretanto a empresa fornece uma gama de serviços ao cliente, tanto no pré-venda e no pós venda. Esses serviços agregados a um produto, levam por definição o termo serviço ao cliente, e por isso, tais atos têm influência na criação e na entrega de valor ao cliente. Dito isso, marketing de serviços é toda e qualquer atividade de marketing direcionada a suprir expectativas esperadas de um serviço (BITNER et al, 2011. LOVELOCK et al, 2011).

Os clientes, quando atendidos por uma empresa, conseguem ver (ilustrar) o atendimento, claro, em seus próprios termos. Esses aspectos percebidos nos pontos de contato, normalmente são emocionais, irracionais, definitivos e humanos. Isto pode representar boas oportunidades aos varejistas, pois, os produtos oferecidos estão cada vez mais similares, a concorrência está cada vez mais acirrada, ou seja, em termos de produtos pode-se dizer que grande parte dos lojistas partem do mesmo nível econômico e competitivo. Por onde é possível se destacar então? Segundo Zamberlan (2010) e Binteret al (2011), o fator determinante na competição das empresas pode estar no serviço oferecido ao cliente, criando experiências de compra satisfatórias e memoráveis, dessa forma estarão agregando cada vez mais valor em seus relacionamentos.

Está acontecendo uma mudança no comportamento dos consumidores, os produtos que antes eram vistos pela ótica da utilidade, agora são vistos como provedores de experiências, e o mesmo se aplica para as empresas. O marketing de experiência, onde a empresa entende de forma profunda seu consumidor, suas expectativas e percepções, por isso a mesma, proporciona o máximo de estímulos positivos, tornando o contato com o cliente satisfatório e memorável. (McKENNA, 2002. SCHMITT, 2002. BREZZO; COBRA, 2010. HILL, 2010). Sendo assim, o marketing de experiências pode ser definido como uma atividade empresarial que estuda, e visa proporcionar experiências de consumo positivas a seus clientes. Apoderando-se das emoções dos clientes, estimulando-os em diversas frentes (racionais e emotivas), gerando respostas emocionais na mente de seus consumidores. 
A experiência do consumo se refere a tudo que acontece de fato entre o cliente e a empresa, adicionado ao que é perceptível na mente do consumidor quando está em contato com a empresa, ou na utilização de algum produto. Dentro de uma experiência de consumo existem diversas variáveis, que podem ser tangíveis, tanto quanto intangíveis (imaginárias e sensoriais). As variáveis racionais podem ser comunicação, preço, distribuição, pessoal treinado, o produto em si. Já as variáveis intangíveis, estão mais ligadas à forma com que o cliente percebe e recebe os estímulos sensoriais na hora do contato com a empresa ou produto, tais como, ambiente, familiarização com o pessoal, a forma com que foi atendido, entre outros. Para se entregar uma boa experiência de compra ao seu cliente, é necessário conhecê-lo muito bem primeiro, entender como ele pensa, se comunica e como ele age (SCHMITT, 2002. McKENNA, 2002. BREZZO; COBRA, 2010).

\subsubsection{Autoatendimento ou autosserviço}

Essa modalidade de negócio, vem ganhando espaço nas empresas varejistas. Nesse formato de venda, o cliente conduz todo o processo de compra, de forma independente. O vendedor necessariamente não é "excluído" do processo, pois em caso de dúvidas o mesmo pode ser solicitado. Esse tipo de serviço, denominando autosserviço, é comum em farmácias, lojas de departamento, restaurantes, entre outros (LAS CASAS, 2002. ZEITHAML et al, 2011. ARANTES, 2012).

\subsubsection{Venda consultiva}

A venda consultiva é um meio de entrega de valor ao cliente. Onde o vendedor atua como um consultor, e entrega soluções que vão além de um simples produto. Isto é, em vendas consultivas não acontece a simples transação de bens ou serviços. $\mathrm{O}$ vendedor, ao iniciar o atendimento, em um primeiro momento identifica o problema por meio de uma conversa interativa. Nesse processo, o consultor de vendas analisa vários pontos na conversa, tais como, gravidade do problema, preço que o cliente está disposto a pagar para uma solução, prazo para a entrega da solução entre outros. Feito isso, chega a hora da oferta da solução (o produto ou o serviço), em acordo com o cliente a venda é finalizada. Caso o cliente não aceite ou não deseje a solução apresentada, cabe ao vendedor buscar em seu portfólio outros produtos ou meios de suprir a necessidade do cliente, até que ambos estejam satisfeitos com a negociação. $O$ profissional que atende o público, deve ter uma comunicação clara, persuasiva e prestativa, vendedor. Esse tipo de venda leva essa nomenclatura pois o vendedor deve perguntar, ouvir e analisar constante as informações que os clientes têm sobre a necessidade (LAS CASAS, 2002. RACHKAM, 2009). 


\subsection{Comportamento do consumidor}

Pode se definir como comportamento do consumidor, um conjunto de variáveis particulares que afetam e tem influência direta nas ações e práticas de aquisições de um indivíduo. Esses fatores podem ser racionais ou irracionais, e pode ser influenciados por diversos elementos, tais como cultura, informação, ações de marketing, histórico, entre outros (KANUK; SCHIFFMAN, 2000).

Conforme descrito nos tópicos anteriores, conhecer o cliente é fundamental para o sucesso das ações de marketing de qualquer empresa. E para isso, é preciso entender seus pensamentos, suas expectativas, influências e memórias. Existe uma área dentro do marketing, denominada neuromarketing, que se dedica a mapear e entender os pensamentos humanos referente as ações de marketing, porém, é preciso cautela, pois os estudos são extremamente recentes, com abordagens ainda um tanto quanto inconclusivas (BREZZO; COBRA, 2010). Mesmo assim, é possível que as empresas possam entender e compreender melhor seu público, entregando as melhores experiências possíveis nos pontos de contato com seus clientes. Para tanto, toda informação do público deve ser utilizada como base para cada ação que se deseja desenvolver ao mercado (BREZZO; COBRA, 2010. HILL, 2010).

Um cliente está atento a tudo, seja de forma consciente ou inconsciente, por isso é tão importante que as empresas tenham um cuidado em relação a percepção de seu público. A percepção do consumidor é o resultado final dos estímulos produzidos no contato com o produto, empresa ou marca. Esses estímulos podem ser oriundos de audição, tato, visão, olfato e paladar. Segundo os autores, o comportamento do consumidor é certamente alterado de acordo com sua percepção. Então, é fundamental que as organizações se esforcem para que as percepções sejam positivas, levando o cliente a ter boas memórias em relação aos produtos e serviços (McKENNA, 1997. SCHMITT, 2002. BOONE; KURTZ, 2010. HILL, 2010)

\section{PROCEDIMENTOS METODOLÓGICOS}

A pesquisa buscou descobrir os benefícios e malefícios na percepção dos consumidores da construção civil sobre dois modelos de venda: o autosserviço e a venda assessorada. A ferramenta de coleta de dados utilizada foi um questionário com uma amostra não probabilística, pois as perguntas foram enviados aleatoriamente por conveniência, de forma virtual. Portanto, segundo Malhotra (2011) e Roesch (2009) esse estudo é classificado como uma pesquisa quantitativa, de acordo com sua natureza. Nele, método de coleta de dados é padronizado, possibilitando ao autor elaborar sumários. Para isso, a análise e tabulação de dados foi feita por meios estatísticos.

Quanto aos fins da pesquisa, esta é definida como exploratória. Assim, ela não é estruturada e tem por objetivo aprofundar o conhecimento sobre determinado tema e, a partir daí, construir uma visão mais clara sobre o objeto de 
estudo. A análise não comportou hipóteses iniciais, contudo, durante o estudo, algumas suposições foram levantadas (VERGARA, 2010. MALHOTRA, 2011).

Para a coleta de dados foi elaborado um questionário no GoogleDocs $\AA$, através da ferramenta de formulários. Em seguida, foi feito um pré-teste com 5 respondentes do público alvo (pessoas que já construíram). Em mãos do préteste, as respostas foram zeradas e a distribuição do formulário iniciou por meio de compartilhamento virtual do link da pesquisa em e-mails e mídias sociais. O período de coleta compreendeu os meses de janeiro e fevereiro de 2019. A pergunta de corte foi se o respondente já havia construído ou reformado, visto que somente assim, poderiam falar de sua real percepção de consumo. A amostra apresentada na ferramenta de formulários é de 185 respostas, entretanto, devido a pergunta de corte, a taxa média de respondentes ficou em 170.

O questionário possuía trinta e uma questões, duas delas descritivas (nome e cidade onde mora), outra de única escolha (escolaridade), vinte e sete questões foram de escala Likert de 5 pontos, em que se buscou medir a frequência das afirmativas, sendo 1 para nenhuma ou muito pouco, e 5 para muito. E por último, uma questão de grade de caixa de seleção, onde o entrevistado classificou categorias de produtos em difícil e fácil compra. Os dados foram tratados e postos em tabelas de frequência, utilizando um software de planilhas para a tabulação dos dados. Já para a análise dos resultados e considerações finais do estudo, o autor utilizou como base a pesquisa bibliográfica.

Como limitações, a pesquisa apresentou as seguintes situações: respostas restritas a pessoas com acesso à internet (já que a distribuição foi online); dificuldade de incentivar o público responder as questões; baixo índice de respostas; os respondentes podem ignorar o recebimento da pesquisa uma vez que o envio do link não feito sob aval do mesmo; desistência de pessoas que consideraram o formulário extenso; entre outros. Ocorrências como essas são comuns em pesquisas que utilizam questionários para de coleta de dados. Por isso, essa pesquisa não favorece a generalização dos dados (MALHOTRA, 2011).

\section{APRESENTAÇÃO E ANÁliSE DOS RESULTADOS}

Neste capítulo, apresenta-se os resultados obtidos com a pesquisa. O estudo buscou analisar os benefícios e malefícios de vendas assessoradas ou por autoatendimento no segmento varejista da construção civil. Primeiramente, buscou-se estabelecer um perfil de idade e a cidade na qual o respondente comprou materiais de construção. 


\begin{tabular}{c|c|c}
\hline ESCALA & FREQUÊNCIA & PERCENTUAL \\
\hline $18 \mid-28$ & 45 & $25 \%$ \\
$28 \mid-38$ & 76 & $42 \%$ \\
$38 \mid-48$ & 36 & $20 \%$ \\
$48 \mid-58$ & 20 & $11 \%$ \\
$58 \mid-68$ & 4 & $2 \%$ \\
$68 \mid-78$ & 4 & $1 \%$ \\
\hline TOTAL & 182 & $100 \%$ \\
\hline
\end{tabular}

Fonte: o autor

Conforme perceptível na Tabela 1, a maioria dos respondentes tem entre 18 e 58 anos. Geralmente, é nessa faixa etária que mais se compram materiais de construção. Dos 18 aos 30 anos é comum que as pessoas iniciem sua primeira construção, como, por exemplo, a casa própria. Em seguida, dos 30 aos 58 anos, iniciam-se as reformas ou "aumentos" nas casas ou apartamentos.

Tabela 2 - Escolaridade

\begin{tabular}{c|c}
\hline ESCOLARIDADE & PERCENTUAL \\
\hline Ensino fundamental incompleto & $2,20 \%$ \\
Ensino fundamental completo & $2,20 \%$ \\
Ensino médio incompleto & $3,30 \%$ \\
Ensino médio completo & $25,30 \%$ \\
Ensino superior incompleto & $29,70 \%$ \\
Ensino superior completo & $37,40 \%$ \\
\hline
\end{tabular}

Fonte: o autor

Conforme apresentado na Tabela 2, a escolaridade dos respondentes se concentra acima do ensino médio completo. Desses, 37,40\% já concluíram o ensino superior, mostrando que os respondentes detêm um grau de instrução elevado.

A pesquisa concentrou-se na cidade de Teutônia e arredores. Sendo assim, conforme Tabela 3, 84,30\% dos respondentes disseram que compraram seus materiais de construção nessa cidade. Agora, outro dado se destaca na pesquisa. A análise mostrou que nenhum dos respondentes comprou materiais de construção pela internet, mesmo com a ascensão do e-commerce em diversos segmentos e a variedade de materiais disponíveis para compra de forma virtual. Uma das possíveis causas para isso pode ser pelo fato de que materiais de construção são produtos técnicos e de grande valor agregado. 
Tabela 3 - Cidade onde comprou seu materiais

\begin{tabular}{c|c}
\hline CIDADE & PERCENTUAL \\
\hline Teutônia & $84,30 \%$ \\
Estrela & $1,70 \%$ \\
Lajeado & $4,10 \%$ \\
Internet & $0 \%$ \\
Outros & $9,90 \%$ \\
\hline
\end{tabular}

Fonte: o autor

Além disso, quase que a totalidade da amostra da pesquisa preferiria comprar os materiais de construção em lojas com venda assessorada, conforme mostrado na Tabela 4 abaixo. Situação que evidencia a complexidade de compra e uso desse tipo de produto.

Tabela 4 - Perfil de atendimento da loja que comprou seus materiais

\begin{tabular}{c|c}
\hline PERFIL & PERCENTUAL \\
\hline Venda assessorada & $97,10 \%$ \\
Autoatendimento & $2,90 \%$ \\
\hline
\end{tabular}

Fonte: o autor

Outra questão que pode demonstrar a dificuldade de compra desse tipo de produto é a frequência de dúvidas que os entrevistados possuíam na hora de comprar os materiais de construção. Para coletar estes dados, as respostas eram em escala, sendo a classe 1 para situações em que raramente tinham dúvidas e a classe 5 para situações em que frequentemente ocorriam indecisões de compra.

Tabela 5 - Frequência de dúvidas

\begin{tabular}{c|c|c}
\hline ESCALA & FREQUÊNCIA & PERCENTUAL \\
\hline 1 & 18 & $11 \%$ \\
2 & 38 & $22 \%$ \\
3 & 51 & $30 \%$ \\
4 & 32 & $19 \%$ \\
5 & 32 & $19 \%$ \\
\hline TOTAL & 171 & $100 \%$ \\
\hline
\end{tabular}

Fonte: o autor.

A Tabela 5 nos mostra que apenas $11 \%$ dos entrevistados raramente tinham ou não ficavam com algum tipo de dúvida na hora de comprar os materiais de construção. Ainda, $58 \%$ das respostas ficaram entre as classes 3 a 5 , corroborando com a hipótese de que materiais de construção não são itens de compra simples. 
Dito isso, é possível que o vendedor ou atendente desempenha um papel importante na compra dos materiais de construção, pois é ele que identifica as necessidades do cliente e em mãos dessas informações apresenta a melhor solução ao seu alcance. Na Tabela 6, são exibidos as respostas em relação à importância que os respondentes da pesquisa dão ao vendedor em suas compras de materiais de construção. As respostas foram em escala de $1 \mathrm{a}$ 5 , sendo 1 para pouco importante e 5 muito importante.

Tabela 6 - Análise do vendedor

\begin{tabular}{|c|c|c|c|c|c|c|}
\hline \multirow[t]{2}{*}{ ESCALA } & \multicolumn{2}{|c|}{$\begin{array}{l}\text { IMPORTÂNCIA DO } \\
\text { ATENDENTE }\end{array}$} & \multicolumn{2}{|c|}{$\begin{array}{c}\text { CONHECIMENTO DO } \\
\text { VENDEDOR }\end{array}$} & \multicolumn{2}{|c|}{$\begin{array}{c}\text { INFLUÊNCIA DO } \\
\text { VENDEDOR NO } \\
\text { RELACIONAMENTO }\end{array}$} \\
\hline & FREQUÊNCIA & PERCENTUAL & FREQUÊNCIA & PERCENTUAL & FREQUÊNCIA & PERCENTUAL \\
\hline 1 & 2 & $1 \%$ & 0 & $0 \%$ & 1 & $1 \%$ \\
\hline 2 & 4 & $2 \%$ & 1 & $1 \%$ & 1 & $1 \%$ \\
\hline 3 & 24 & $14 \%$ & 2 & $1 \%$ & 8 & $5 \%$ \\
\hline 4 & 40 & $24 \%$ & 17 & $10 \%$ & 37 & $21 \%$ \\
\hline 5 & 100 & $59 \%$ & 153 & $88 \%$ & 126 & $73 \%$ \\
\hline TOTAL & 171 & $100 \%$ & 173 & $100 \%$ & 173 & $100 \%$ \\
\hline
\end{tabular}

Fonte: o autor.

Nota-se a relevância que o vendedor ou atendente de materiais de construção tem para os respondentes. Visto que, na Tabela 6 a grande maioria das pessoas que responderam ao questionário marcaram a opção 5 , isto é, muito importante. Esse dado mostra que o vendedor é fundamental para a compra de materiais de construção, já que ao darem peso a importância do vendedor, 59\% dos entrevistados escolheram o critério máximo (muito importante), e quando foi pedido para avaliarem a importância do conhecimento técnico do vendedor nesse tipo de produto, $88 \%$ também declaram ser muito importante a instrução do vendedor. Ademais, $73 \%$ dos entrevistados nessa questão pensam que o vendedor exerce grande influência no relacionamento que o cliente tem com a empresa fornecedora.

Como já apurado, os produtos vendidos nas lojas varejistas da construção civil, em sua maioria, são mercadorias de aplicabilidade técnica. Ou seja, não é um produto pronto para o consumo. Temos como exemplo o cimento, em que o cliente compra o produto e o usa na obtenção de outras soluções como muros, rebocos, vigas, calçadas e outros. Por isso, essa questão foi levada em conta no questionário, em que buscou-se medir a periodicidade das vezes em que o entrevistado teve que ser instruído sobre o uso correto do produto pelo atendente da loja. Novamente, as respostas foram em escala de 1 a 5 , sendo 1 para raramente teve que ser instruído e 5 para frequentemente precisou da indicação do vendedor. Na tabela 7 pode-se ver os resultados: 
Tabela 7 - Necessidade de instrução do atendente

\begin{tabular}{c|c|c}
\hline ESCALA & FREQUÊNCIA & PERCENTUAL \\
\hline 1 & 12 & $7 \%$ \\
2 & 11 & $6 \%$ \\
3 & 40 & $23 \%$ \\
4 & 57 & $33 \%$ \\
5 & 51 & $30 \%$ \\
\hline TOTAL & 171 & $100 \%$ \\
\hline
\end{tabular}

Fonte: o autor.

É possível observar na Tabela 7 que apenas 13\% dos entrevistados permaneceram abaixo do ponto médio da escala. Isto é, somente esses 23 entrevistados não precisaram de muita instrução do atendente. $\mathrm{O}$ restante, que totalizam $86 \%$ da amostra, permaneceram do ponto médio ao ponto máximo da escala. Ou seja, $23 \%$ dos entrevistados marcaram o ponto 3, mostrando que houve situações de instrução do vendedor, mas que não foram muitas, aproximadamente metade das vezes. Entretanto, 33\% ficam no ponto 4 da escala, mostrando que em diversas vezes precisaram da ajuda do vendedor. Além disso, $30 \%$ do público afirmou que frequentemente tinham dúvidas do uso correto do produto e precisaram do conhecimento técnico do profissional que os atendia.

Com o cenário econômico concorrido, é natural que surjam diversas marcas e diversos tipos de produtos similares ou substitutos. E não é diferente no segmento de construção civil, para cada produto existe uma variedade de marcas, além disso, para alguns produtos, além da opção de escolha de marca, existem opções de produtos substitutos. Pensando nisso, foram levantados duas questões, em escala de 1 a 5, em que foi medido a frequência das situações em que o vendedor aconselhou sobre marcas e qualidade dos produtos e a outra sobre a indicação de produtos complementares (muitas vezes fundamentais), como aditivos impermeabilizantes. Sendo a opção 1 para raramente acontece e na outra ponta a opção 5 , onde frequentemente acontecia. 
Tabela 8 - Indicação de marcas e produtos complementares

\begin{tabular}{c|c|c|c|c}
\hline \multirow{2}{*}{ ESCALA } & \multicolumn{2}{|c|}{$\begin{array}{c}\text { INFLUENCIA DO VENDEDOR SOBRE } \\
\text { MARCAS QUALIDADE }\end{array}$} & $\begin{array}{r}\text { INDICAÇÃO DE PRODUTOS } \\
\text { COMPLEMENTARES PELO } \\
\text { VENDEDOR }\end{array}$ \\
\cline { 2 - 5 } & FREQUÊNCIA & PERCENTUAL & FREQUÊNCIA & PERCENTUAL \\
\hline 1 & 7 & $4 \%$ & 16 & $9 \%$ \\
2 & 9 & $5 \%$ & 23 & $14 \%$ \\
3 & 40 & $23 \%$ & 46 & $27 \%$ \\
4 & 66 & $39 \%$ & 50 & $29 \%$ \\
5 & 49 & $29 \%$ & 35 & $21 \%$ \\
\hline TOTAL & 171 & $100 \%$ & 170 & $100 \%$ \\
\hline
\end{tabular}

Fonte: o autor.

Em conformidade com a Tabela 8, pode-se dizer que mais da metade dos respondentes disseram que as vezes que os vendedores influenciavam entre marcas e os produtos eram rotineiras nas compras, visto que a maioria das respostas se concentra do ponto médio ao extremo (frequentemente), correspondendo $39 \%$ ao peso 4 (quase frequentemente) e $29 \%$ demonstraram que a influência do vendedor sob marcas e determinados produtos era constante. Além de que, os entrevistados (em sua maioria) também demonstraram que os atendentes indicavam produtos complementares constantemente, já que mais da metade das respostas se encontra no ponto médio ao alto dentro da escala.

Por se tratar de produtos de complexidade técnica, comprar materiais de construção pode levar um tempo maior em relação a outros tipos de produto. A seguir, a Tabela 9 apresenta as respostas da questão que buscou medir o tempo percebido que o respondente gastou em suas compras dos materiais de construção.

Tabela 9 - Tempo para a compra de materiais de construção

\begin{tabular}{c|c|c}
\hline ESCALA & FREQUÊNCIA & PERCENTUAL \\
\hline 1 & 19 & $11 \%$ \\
2 & 42 & $25 \%$ \\
3 & 82 & $48 \%$ \\
4 & 16 & $9 \%$ \\
5 & 11 & $6 \%$ \\
\hline TOTAL & 171 & $100 \%$ \\
\hline
\end{tabular}

Fonte: o autor.

Como é possível notar, os respondentes em sua maioria não julgaram despender muito tempo para suas compras de materiais de construção. Isso mostra que, mesmo em uma venda assessorada (97,10\% dos casos), o tempo gasto escolhendo produtos de materiais de construção não é grande, segundo os respondentes, já que a maioria das respostas se concentrou do ponto médio ao ponto mais baixo da escala, totalizando $36 \%$ em pouco tempo, e $48 \%$ em 
tempo médio, e apenas $15 \%$ consideraram gastar muito tempo ao comprar materiais de construção.

Como visto na pesquisa, o vendedor exerce um papel significativo nas vendas dos materiais de construção. Contudo, por se tratar de atendimentos personalizado (já que as necessidades são muito distintas), e também por se tratar de seres humanos, em que o comportamento (entende-se qualidade no atendimento) pode alterar de acordo com inúmeros estímulos, podem ocorrer algumas falhas. Por isso, a Tabela 10 corresponde a três questões. Sendo também em escala, em que a pontuação 1 se refere a nenhuma ou poucas vezes e a pontuação 5 se refere a muitas vezes.

Tabela 10 - FALHAS do vendedor.

\begin{tabular}{|c|c|c|c|c|c|c|}
\hline \multirow[t]{2}{*}{ ESCALA } & \multicolumn{2}{|c|}{$\begin{array}{c}\text { FALTA DE } \\
\text { CONHECIMENTO DO } \\
\text { VENDEDOR }\end{array}$} & \multicolumn{2}{|c|}{ ERRO DO VENDEDOR } & \multicolumn{2}{|c|}{$\begin{array}{c}\text { VENDEDOR INDUZIU AO } \\
\text { ERRO }\end{array}$} \\
\hline & FREQUÊNCIA & PERCENTUAL & FREQUÊNCIA & PERCENTUAL & FREQUÊNCIA & PERCENTUAL \\
\hline 1 & 56 & $33 \%$ & 69 & $40 \%$ & 92 & $54 \%$ \\
\hline 2 & 50 & $29 \%$ & 51 & $30 \%$ & 48 & $28 \%$ \\
\hline 3 & 40 & $24 \%$ & 30 & $18 \%$ & 15 & $9 \%$ \\
\hline 4 & 14 & $8 \%$ & 10 & $6 \%$ & 10 & $6 \%$ \\
\hline 5 & 10 & $6 \%$ & 11 & $6 \%$ & 6 & $4 \%$ \\
\hline TOTAL & 170 & $100 \%$ & 171 & $100 \%$ & 171 & $100 \%$ \\
\hline
\end{tabular}

Fonte: o autor.

Apesar de se tratar de comportamento humano (algumas vezes imprevisível e reagente a estímulos externos), de modo geral, é possível dizer que os vendedores das cidades que se baseou o estudo, possuem boa capacidade técnica. Uma vez que a maioria das respostas das três questões que buscavam analisar possíveis falhas dos atendentes, se concentrou do ponto médio ao ponto baixo da escala. Sendo que $62 \%$ dos respondentes disseram que houve poucas vezes ou nenhuma que o vendedor não soube ajudar. Além disso, 70\% dos entrevistados responderam que houve poucos erros ou nenhum por parte dos vendedores. Somado a isso, $82 \%$ dos respondentes mencionaram que os atendentes induziram poucas vezes ou nenhuma ao erro, como por exemplo "empurrar" um material desnecessário na venda.

Essa pesquisa buscou também analisar as distinções na experiência de consumo entre varejistas de autoatendimento e venda assessorada na construção civil. Sendo assim, foram levantadas questões que medem critérios de importância para diversas situações que os dois modelos de negócio oferecem. Sendo assim, foi possível medir as percepções para cada circunstância apresentada. As Tabelas 11 e 12 se referem a elas: 
Tabela 11 - Percepções das situações

\begin{tabular}{c|c|c|c|c|c|c|c|c}
\hline \multirow{2}{*}{ ESCALA } & \multicolumn{2}{|c|}{$\begin{array}{c}\text { AGILIDADE NO } \\
\text { ATENDIMENTO }\end{array}$} & \multicolumn{2}{|c|}{\begin{tabular}{l} 
AUTONOMIA DAS COMPRAS \\
\cline { 2 - 8 }
\end{tabular}} & $\begin{array}{c}\text { ALOCAÇÃO DOS PRODUTOS } \\
\text { NA LOA }\end{array}$ & \multicolumn{2}{c}{ CONFIANÇA NO VENDEDOR } \\
\cline { 2 - 9 } & FREQUENCIA & PERCENTUAL & FREQUÊNCIA & PERCENTUAL & FREQUÊNCIA & PERCENTUAL & FREQUÊNCIA & PERCENTUAL \\
\hline 1 & 2 & $1 \%$ & 21 & $12 \%$ & 0 & $0 \%$ & 1 & $1 \%$ \\
2 & 4 & $2 \%$ & 28 & $16 \%$ & 3 & $2 \%$ & 0 & $0 \%$ \\
3 & 18 & $10 \%$ & 60 & $35 \%$ & 13 & $8 \%$ & 10 & $6 \%$ \\
4 & 41 & $24 \%$ & 32 & $19 \%$ & 31 & $18 \%$ & 34 & $19 \%$ \\
5 & 108 & $62 \%$ & 31 & $18 \%$ & 126 & $73 \%$ & 131 & $74 \%$ \\
\hline TOTAL & 173 & $100 \%$ & 172 & $100 \%$ & 173 & $100 \%$ & 176 & $100 \%$ \\
\hline
\end{tabular}

Fonte: o autor.

Tabela 12 - Percepções das situações

\begin{tabular}{c|c|c|c|c|c|c|c|c}
\hline & \multicolumn{2}{|c|}{ VARIEDADE DE PRODUTOS } & \multicolumn{2}{|c|}{$\begin{array}{c}\text { ACESSO DIRETO AOS } \\
\text { PRODUTS }\end{array}$} & \multicolumn{2}{c|}{ LAYOUT DA LOJA } & \multicolumn{2}{c}{$\begin{array}{c}\text { RELACIONAMENTO COM A } \\
\text { EMPRESA OU VENDEDOR }\end{array}$} \\
\hline ESCALA & FREQUÊNCIA & PERCENTUAL & FREQUÊNCIA & PERCENTUAL & FREQUÊNCIA & PERCENTUAL & FREQUÊNCIA & PERCENTUAL \\
\hline 1 & 0 & $0 \%$ & 0 & $0 \%$ & 0 & $0 \%$ & 0 & $0 \%$ \\
2 & 2 & $1 \%$ & 1 & $1 \%$ & 2 & $1 \%$ & 1 & $1 \%$ \\
3 & 6 & $3 \%$ & 20 & $11 \%$ & 17 & $10 \%$ & 14 & $8 \%$ \\
4 & 36 & $21 \%$ & 50 & $28 \%$ & 55 & $32 \%$ & 45 & $26 \%$ \\
5 & 131 & $75 \%$ & 105 & $60 \%$ & 100 & $57 \%$ & 115 & $66 \%$ \\
\hline TOTAL & 175 & $100 \%$ & 176 & $100 \%$ & 174 & $100 \%$ & 175 & $100 \%$ \\
\hline
\end{tabular}

Fonte: o autor.

As Tabela 11 e 12 apontam que, mesmo os entrevistados prefiram vendas assessoradas, existem situações do autoatendimento que os mesmos valorizam, tais como agilidade em fazer compras em materiais de construção. Neste quesito, $86 \%$ marcaram importante e muito importante. Os respondentes gostam também de ter acesso direto a todos os produtos da loja, sem necessariamente passar por um balcão ou vendedor. Dessa questão, $88 \%$ marcaram entre importante e muito importante. No quesito, variedade de produtos, $96 \%$ dos entrevistados marcaram importante e muito importante.

Já uma boa disposição dos produtos e um bom layout da loja também são julgados importante e muito importante segundo os entrevistados, ficando entre $91 \%$ na questão da alocação dos produtos no espaço interno do estabelecimento e $89 \%$ para o layout de vendas da loja. Em outros dois pontos, os resultados também se mantiveram na escala de importante ou muito importante. O quesito confiança no vendedor ficou com $93 \%$ e a questão sobre o relacionamento com a empresa e vendedor com $92 \%$. Esses resultados sugerem que os respondentes têm preferências por situações que não acontecem no autoatendimento, como a segurança de um atendimento humano e consultivo. Dado que foi feita uma pergunta simples e direta, sobre a preferência de compra entre os dois modelos de atendimento, o resultado é apresentado na Tabela 13: 
Tabela 13 - Preferência de compra

\begin{tabular}{c|c}
\hline PREFERÊNCIA DE COMPRA: AUTOATENDIMENTO X VENDA & PERCENTUAL \\
\hline $\begin{array}{c}\text { ASSESSORADA } \\
\text { Loja com vendedor (um atendente que te ajuda na escolha dos } \\
\text { produtos) }\end{array}$ & $96,50 \%$ \\
Loja de Autoatendimento (sem interferência de vendedor) & $3,50 \%$ \\
\hline TOTAL & $100 \%$ \\
\hline
\end{tabular}

Fonte: $\mathrm{o}$ autor.

Esse cenário resulta em implicações gerenciais para as empresas do segmento, dessa forma buscou-se identificar qual seria o modelo de negócio ideal na percepção dos respondentes. Para isso, foram expostas diversas categorias de produtos, nas quais os entrevistados deveriam escolher se o que era apresentado era de fácil compra (poderia ser vendido em autoatendimento) ou de difícil compra (é necessário um vendedor para assessorar sobre qual produto escolher ou qual seu uso correto). Dito isso, a Tabela 14 apresenta os resultados obtidos.

Tabela 14 - Categorias de produtos e suas compras

\begin{tabular}{c|c|c|c|c|c|c}
\hline PRODUTOS & $\begin{array}{c}\text { FÁCIL } \\
\text { COMPRA }\end{array}$ & $\begin{array}{c}\text { DIFÍCIL } \\
\text { COMPRA }\end{array}$ & TOTAL & FÁCIL & DIFÍCIL & RESULTADO \\
\hline Cimentos, argamassas e colantes & 105 & 66 & 171 & $61 \%$ & $39 \%$ & Fácil \\
Ferros estruturais & 71 & 99 & 170 & $42 \%$ & $58 \%$ & Difícil \\
Parafusos e pregos & 125 & 46 & 171 & $73 \%$ & $27 \%$ & Fácil \\
Colas e silicones & 93 & 78 & 171 & $54 \%$ & $46 \%$ & Fácil \\
Ferramentas & 104 & 68 & 172 & $60 \%$ & $40 \%$ & Fácil \\
Madeiras para formas e caixas & 72 & 97 & 169 & $43 \%$ & $57 \%$ & Difícil \\
Madeiras para vigamentos e & 53 & 114 & 167 & $32 \%$ & $68 \%$ & Difícil \\
telhados & 55 & 114 & 169 & $33 \%$ & $67 \%$ & Difícil \\
Telhas e coberturas & 43 & 126 & 169 & $25 \%$ & $75 \%$ & Difícil \\
Impermeabilizantes & 101 & 69 & 170 & $59 \%$ & $41 \%$ & Fácil \\
Blocos, pedras e tijolos & 53 & 117 & 170 & $31 \%$ & $69 \%$ & Difícil \\
Revestimentos de chão e parede & 52 & 117 & 169 & $31 \%$ & $69 \%$ & Difícil \\
Material hidráulico e elétrico & $57 \%$ & 74 & 171 & $57 \%$ & $43 \%$ & Fácil \\
Insumo concretos e massas (areia e & 97 & &
\end{tabular}

Fonte: o autor.

Conforme descrito na Tabela 14, as categorias cimentos e derivados, parafusos e pregos, colas e silicones, ferramentas, tijolos e blocos, matériaprima para concretos e massas permaneceram entre os produtos de fácil compra. Isto é, esses produtos, segundo os respondentes, não necessitam de um vendedor para se fazer a compra certa. Já os produtos que segundo os entrevistados, é necessário um vendedor auxiliando na compra são: ferros estruturais, madeiras, telhas e coberturas, impermeabilizantes, revestimentos e material hidráulico. Seguindo os parâmetros dos resultados das questões de 
percepção de consumo foi possível montar um formato de atendimento do que os respondentes esperam de uma loja de materiais de construção, conforme a Figura 1:

Figura 1 - Modelo de loja de materiais de construção

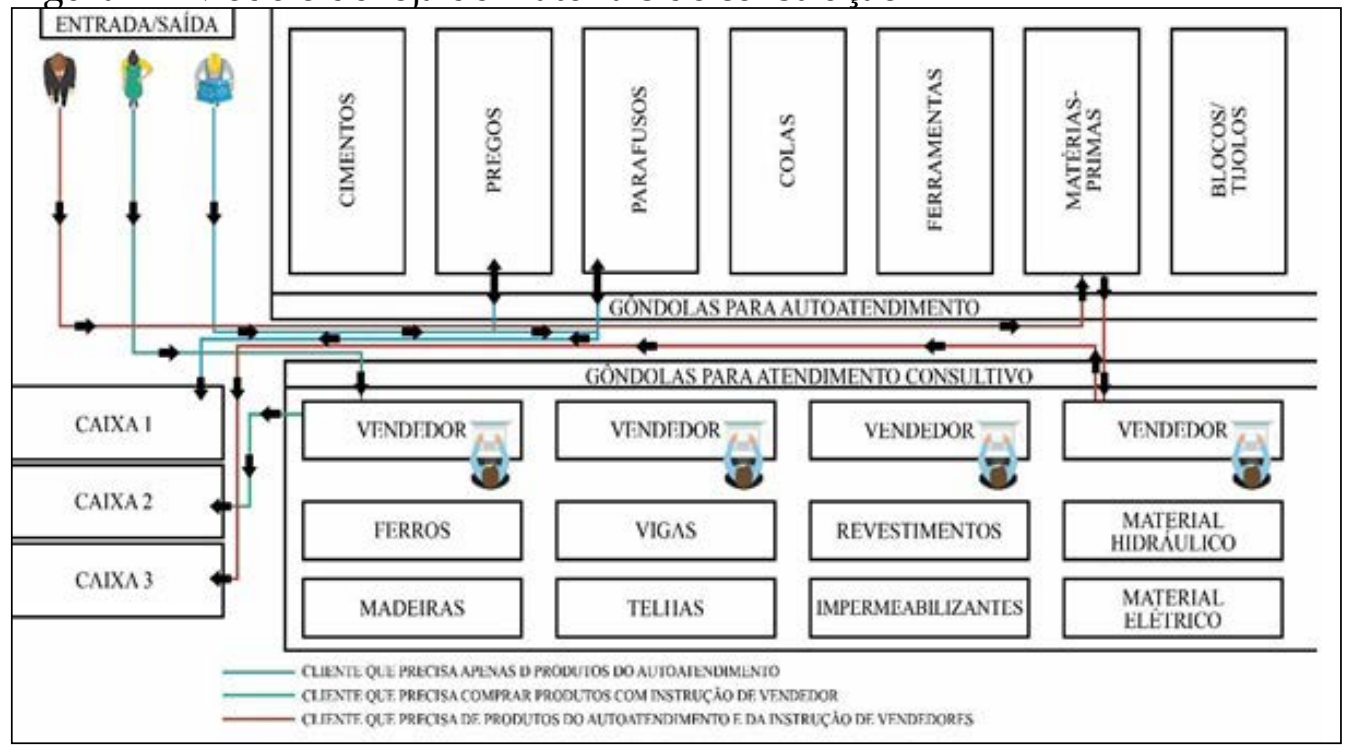

Fonte: o autor.

Nesse formato, foram simulados três possíveis cenários de compra. $\mathrm{O}$ primeiro, de cor vermelha é um cliente que possui uma lista de produtos a serem comprados para sua obra. Parte desses itens, ele acredita que consegue comprar sozinho, tais como pregos, cimentos e ferramentas. Os demais, por outro lado, ele precisa da ajuda do vendedor para decidir sobre qual é o produto mais indicado para sua necessidade. Em seguida, se dirige aos caixas para pagar e levar seus produtos, ou confirmar a entrega.

O segundo cliente, de cor verde, precisa somente de um produto da seção autoatendimento e geralmente não quer despender muito tempo em sua compra. Por isso, vai direto às gôndolas, pega o produto desejado, se dirige ao caixa e finaliza o atendimento.

O terceiro cliente precisa de produtos de difícil compra. Sendo assim, precisa do auxílio e instrução do vendedor para fazer a melhor escolha. Feito isso, se dirige ao caixa, paga e leva seu produto ou confirma sua entrega.

Essa ilustração, é uma projeção do que seria um formato ideal de loja, levando em conta a independência de interação com os clientes nos ambientes. Ou seja, um cliente que já sabe o que precisa, não precisa perder tempo passando o pedido com um vendedor, se ele já pode ir direto no caixa. E da mesma forma, 
um cliente que precisa da ajuda do atendente, não precisa desperdiçar tempo procurando produtos e lendo rótulos dos quais não entende.

\section{CONSIDERAÇÕES FINAIS}

O estudo se propôs a verificar as vantagens e desvantagens na percepção dos consumidores de empresas varejistas que atendem com autosserviço e por vendas consultivas. O segmento econômico da pesquisa foi a construção civil. Posto isso, através dos resultados da pesquisa empírica foi possível responder a problemática do artigo.

Entende-se que os produtos desse segmento, geralmente são produtos mais técnicos, em que são "ingredientes" para obtenção de outros produtos. A telha é um exemplo disso, em que a mesma é adquirida não como produto final, mas sim meio de se obter um telhado ou cobertura. Por isso, com a complexidade do tipo de compra que os produtos da construção civil apresentam, os entrevistados geralmente tinham dúvidas de escolha. Por essa razão, optaram em comprar com a instrução de um atendente, evidenciando que o vendedor é uma peça fundamental nesse segmento (LAS CASAS, 2002; RACKHAM, 2009). Os vendedores, segundo os respondentes, exercem grande influência sobre os consumidores, mostrando que os mesmos detêm a confiança de seus clientes. Portanto, em termos gerais, os resultados mostraram que a maciça maioria dos respondentes prefere comprar seus produtos com a assessoria de um vendedor. O que mostra que os mesmos não estão centrados apenas na simples compra de um bem material, o que pode ser percebido na avaliação do tempo despendido nas compras, já que os respondentes consideram que gastaram pouco tempo, mesmo sendo uma venda assessorada por um vendedor, sendo interpretado como um reconhecimento dos benefícios da interação humana. Inicialmente, o tempo de compra poderia ser uma desvantagem de uma venda consultiva, porém passa despercebido, pois não diminui a satisfação da experiência de compra. Consolidando a onda crescente de clientes que focam seus olhares cada vez mais para experiências ao invés de características de produtos (SCHIMITT, 2002. BREZZO; COBRA 2010. BITNER et al, 2011).

A escolha dos entrevistados pela proximidade com o vendedor nas compras em materiais de construção apresentada na análise, vem da busca de relacionamentos entre consumidores e empresas (McKENNA, 1997. GORDON, 1998. KOTLER, 2007). Segundo os autores, esse comportamento pode representar oportunidades as organizações, fazendo com que os relacionamentos nascidos de vendas consultivas perdurem por longos períodos.

Outro ponto que vale ser ressaltado, é quanto aos possíveis erros que um atendimento traria. Situação que se provou inversa, pois, segundo os dados do questionário, foram poucas falhas que aconteceram por parte dos atendentes, o que mostra a eficiência de uma venda consultiva, uma vez que o vendedor passou a conhecer bem seu cliente, diminuindo assim as chances de erros e 
fortalecendo o relacionamento (McKENNA, 1997. LAS CASA, 2002. KOTLER, 2007. BREZZO; COBRA, 2010 ).

A partir da análise das percepções de consumo dos entrevistados, foi possível perceber que ambos os tipos de atendimento analisados no estudo têm pontos positivos. Além disso, os mesmos podem ser encontrados simultaneamente nos dois modelos de vendas. Agora, um aspecto que ficou claro na pesquisa, é a segurança passada pelo atendente aos clientes nas explicações sobre os produtos. Ou seja, os clientes se sentiam mais seguros a realizarem compras com a instrução de um vendedor. Mostrando que, esse é um dos principais benefícios desse tipo de atendimento. Logo, se torna um ponto negativo ao modelo de autosserviço, visto que não existe um vendedor analisando a fundo a necessidade do cliente, sendo o próprio cliente o responsável pelo êxito da compra, o que, na percepção dos entrevistados, gera incertezas.

Respondendo a problemática do artigo, a melhor forma de comprar materiais de construção com base na pesquisa, é por meio de uma venda assessorada. Para o público, os principais motivos que levam a escolha desse tipo de atendimento são: segurança na compra e valorização do relacionamento com a empresa, e, consequentemente, com seus atendentes. O que mostra que os consumidores não procuram mais produtos e sim soluções e experiências (McKENNA, 1997. SCHIMITT, 2002. KOTLER, 2007. HILL, 2010. BITNER et al, 2011). Todavia, a análise dos dados mostrou que o autosserviço também apresenta benefícios, tais como agilidade, praticidade e independência. À vista disso, recomenda-se um perfil de atendimento híbrido, em que produtos avaliados de fácil escolha de compra, fiquem dispostos em gôndolas de autoatendimento, e produtos considerados de difícil discernimento de compra, sejam oferecidos por vendedores consultores.

\section{REFERÊNCIAS}

ARANTES, Elaine Cristina. Marketing de serviços. Curitiba: Ibpex, 2012. Disponível em: <https://search.ebscohost.com/login.aspx?direct=true\&db=cat05853a\&AN=uni. 9788582123928\&lang=pt-br\&site=eds-live\&scope=site>. Acesso em: 26 fev. 2019.

BOONE, Louis E.; KURTZ, David L. Marketing contemporâneo. São Paulo: Cengage Learning, 2009.

COBRA, Marcos. Marketing Básico: uma perspectiva brasileira. São Paulo: Atlas, 1997.

COBRA, Marcos; BREZZO, Roberto. O novo marketing. Rio de Janeiro: Elsevier, 2010.

GIL, Antonio Carlos. Estudo de caso. São Paulo: Atlas, 2009. 
GORDON, Ian. Marketing de relacionamento: estratégias, técnicas e tecnologia para conquistar clientes e mantê-los para sempre. São Paulo: Futura, 1998.

GUMMESSON, Evert. Marketing de relacionamento total. 3. ed. Porto Alegre: Bookman, 2010.

HILL, Dan. Emotionomics: por que o sentimento dos clientes pela sua marca determina o sucesso do seu negócio. Rio de Janeiro: Elsevier, 2010.

KARSAKLIAN, Eliane. Comportamento do consumidor. 2. ed. São Paulo: Atlas, 2011.

KOTLER, Philip; ARMSTRONG, Gary. Princípios de marketing. 5a ed. Rio de Janeiro: PearsonPretience Hall, 2007.

LAS CASAS, Alexandre Luzzi. Administração de vendas. São Paulo: Atlas 2002.

LAS CASAS, Alexandre Luzzi. Marketing de Serviços. $3^{\text {a }}$ ed. São Paulo: Editora Atlas, 2002.

LEWIS, David; BRIDGES, Darren. A alma do novo consumidor. São Paulo: M. Books do Brasil, 2004.

LOVELOCK, Christopher; WIRTZ, Jochen; HEMZO, Miguel Angelo. Marketing de serviços: pessoas, tecnologia e estratégia. 7. ed. São Paulo: Pearson Prentice Hall, 2012.

MADRUGA, Roberto. Guia de implementação de marketing de relacionamento e CRM: o que e como todas as empresas brasileiras devem fazer para conquistar, reter e encantar seus clientes. 2. ed. São Paulo: Atlas, 2010.

MALHOTRA, Naresh. Pesquisa de Marketing: Foco na decisão. 3.ed. São Paulo: Pearson, 2011.

MCKENNA, Regis. Marketing de relacionamento: Estratégias bem-sucedidas para a era do cliente. Rio de Janeiro: Elsevier Brasil, 1997.

PESQUISA Nacional por Amostra de Domicílios. IBGE. Rio de Janeiro, 2013. v. 33. Disponível em: <http://biblioteca.ibge.gov.br/visualizacao/periodicos/59/ pnad_2013_v33_br.pdf $>$. Acesso em: 2 fev. 2019

RACKHAM, Neil. Alcançando Excelência em Vendas: SPIN Selling. Construindo Relacionamento de Alto valor para seus Clientes. São Paulo: M. Books do Brasil, 2009.

SCHIFFMAN, Leon G.; KANUK, Leslie Lazar; AMBRÓSIO, Vicente. Comportamento do consumidor. 6. ed. Rio de Janeiro: LTC, c2000.

SCHMITT, Bernd. H. Customerexperience management. Hoboken: Wiley, 2003. 
SCHMITT, Bernd. H. Marketing experimental. São Paulo: Nobel, 2002.

VERGARA, Sylvia Constant. Métodos de Pesquisa em Administração. 4. Ed. São Paulo: Atlas, 2010.

ZEITHAML, Valarie A.; BITNER, Mary Jo; GREMLER, Dwayne D. Marketing de serviços: a empresa com foco no cliente. 5. ed. Porto Alegre: Bookman, 2011. 